\title{
O COMPORTAMENTO DA RECEITA PÚBLICA MUNICIPAL: UM ESTUDO DE CASO NO MUNICÍPIO DE PARNAÍBA - PI ${ }^{1}$
}

\author{
PUBLIC MUNICIPAL REVENUE PERFORMACE: A CASE STUDY IN THE CITY OF \\ PARNAÍBA - PI, BRAZIL
}

\section{EL COMPORTAMIENTO DEL RÉDITO PÚBLICO MUNICIPAL: UN ESTUDIO DEL CASO EN LA CIUDAD DE PARNAÍBA - PI, BRASIL}

\author{
Horlânia de Sousa Brito, Especialista em Gestão em Contabilidade Pública pela \\ Universidade Estadual do Piauí (UESPI). Graduada em Ciências Econômicas pela UFPI. \\ Endereço Profissional: Rua México, 168, Rodoviária, CEP: 64212-165. Parnaíba - PI. E- \\ mail: horlaniabritoeconomista@gmail.com
}

Ricjardeson Rocha Dias, Especialista em Contabilidade Pública pela Universidade Federal do Piauí (UFPI). Endereço Profissional: Gescon Cursos, Rua Arlindo Nogueira ${ }^{\circ} 333$, Edifício Luís Fortes, Sala 08, Centro, Teresina, PI - Brasil. CEP 64000903. Telefone (086) 33059102. Email: ricjardeson@gmail.com

\section{RESUMO}

A Receita Pública Municipal, formada em grande parte pelas receitas tributárias e de transferências intergovernamentais, é a mola propulsora das atividades de responsabilidade das gestões locais, que tem como finalidade o bem-estar da população alcançada. Neste sentido, torna-se importante analisar o comportamento das receitas em diferentes Municípios. Este trabalho analisou o comportamento da Receita Pública Municipal em Parnaíba - PI no decênio 2003-2012. Os objetivos traçados para este atividade foram: revelar a dinâmica de arrecadação das receitas tributárias e de transferências intergovernamentais em Parnaíba - PI no período estudado e demonstrar uma possível condição de dependência financeira em relação às transferências intergovernamentais. A metodologia utilizada contemplou documentos e bibliografias afins, teve como formas de abordagem as pesquisas qualitativas e quantitativas e a coleta de dados, envolveram informações em meio digital e entrevistas não padronizadas. Os resultados demonstram elevação na arrecadação da maior parte das receitas, apesar das grandes oscilações, os destaques em volume de recolhimento foram ISSQN e FPM, receita tributária e de transferências intergovernamentais, respectivamente e comprovou-se a existência de dependência financeira em relação às transferências intergovernamentais.

Palavras-chave: Comportamento; Receita Municipal; Receita Tributária; Receita de Transferências Intergovernamentais.

\footnotetext{
${ }^{1}$ Artigo submetido em 27/05/2015, revisado em 19/10/2015, aceito em 02/04/2016 e divulgado em 30/06/2016 pelo Editor João Carlos Hipólito Bernardes do Nascimento, após double blind review.
}

GєECont, v.3, n.1, Floriano-PI, Jan-Jun. 2016. 


\begin{abstract}
The Municipal Public Revenue, formed largely by tax revenue and intergovernmental transfers, is the main force of the responsibility activities of local administrations, which aims, the well-being of the population reached. In this sense, it is important to analyze the behavior of income in different municipalities. This study analyzed the behavior of the Municipal Public Revenue in Parnaiba - PI, in the decade 2003-2012. The aimed for this activity were: to reveal the dynamics of collection of tax revenues and intergovernmental transfers in Parnaiba - PI in the period studied and demonstrate a possible condition of financial dependence on intergovernmental transfers. The methodology used contemplated documents and related bibliographies, had as forms of qualitative and quantitative research approach and data collection involved information in digital means, not standardized interviews. The results show rise in revenues of most of the revenue, despite large fluctuations, the highlights in volume collection were ISSQN and FPM, tax revenue and intergovernmental transfers, respectively and proved the existence of financial dependence on intergovernmental transfers.
\end{abstract}

Keywords: Behavior; Municipal revenue; Tax revenue; Revenue Intergovernmental Transfers.

\title{
RESUMEN
}

La Ingresos Públicos Municipales, formada en gran parte por los ingresos tributarios y las transferencias intergubernamentales, es la fuerza motriz de las actividades de responsabilidad de las administraciones locales, cuyo objetivo, el bienestar de la población alcanzó. En este sentido, es importante analizar el comportamiento de los ingresos en los diferentes municipios. Este estudio analiza el comportamiento de la Ingresos Públicos Municipales en Parnaíba - PI en la década 2003-2012. Los objetivos establecidos para esta actividad fueron: para revelar la dinámica de la recaudación de los ingresos tributarios y las transferencias intergubernamentales en Parnaíba - PI en el período estudiado y demostrar una posible condición de dependencia financiera de las transferencias intergubernamentales. La metodología utilizada documentos contemplados y bibliografías relacionadas, tuvo como formas de enfoque de investigación y recopilación de datos de información involucrados cualitativa y cuantitativa en medios digitales, no entrevistas estandarizadas. Los resultados muestran aumento de los ingresos de la mayoría de los ingresos, a pesar de las grandes fluctuaciones, los aspectos más destacados de la colección volumen fueron ISSQN y FPM, los ingresos fiscales y las transferencias intergubernamentales, respectivamente y demostrado la existencia de dependencia financiera de las transferencias intergubernamentales.

Palabras clave: Comportamiento. Ingresos municipales. Los ingresos tributarios. Transferencias de Ingresos Intergubernamentales.

\section{INTRODUÇÃO}

$\mathrm{P}_{\mathrm{s}}$ ara que o Estado alcance sua finalidade maior, o planejamento deve guiar as ações dos gestores públicos. Segundo Chiavenato (2001): "planejar é definir os objetivos e escolher antecipadamente o melhor curso de ação para alcançá-los".

Vê-se que planejar é diminuir a possibilidade de cometer falhas.

Em se tratando da gestão pública de recursos financeiros, o maior fruto do processo de planejamento é o que se denomina Orçamento Público, previsto na Constituição Federal de GєECont, v.3, n.1, Floriano-PI, Jan-Jun. 2016. 
1988, recebendo contribuições das Leis 4.320/64 e 101/2000, pode ser definido como a estimativa de receitas e fixação de despesas dos poderes: Executivo, Legislativo e Judiciário; que é realizado de forma individualizada por cada ente federado (União, Estados, Distrito Federal e Municípios) (BRASIL, 1988) (BRASIL, 1964) (BRASIL, 2000).

O Orçamento Público é, simplificadamente, um meio de transformar as arrecadações públicas em uma determinada estrutura de gastos, terminando por espelhar decisões políticas, pois estabelece ações prioritárias para atendimento das demandas sociais, em face da escassez de recursos (ALVES, 2013).

Além do respeito devido às leis do Orçamento Público, outro instrumento que representa grande avanço no tocante a administração de recursos públicos é a Lei de Responsabilidade Fiscal - LRF (Lei Complementar 101/2000). Esta lei objetiva o controle de gastos e endividamento excessivo por parte dos governos subnacionais (estados e municípios), pois se acredita que ao atingir o controle e o equilíbrio permanentes das contas públicas dos citados entes, haverá melhores condições para o crescimento sustentado (BRASIL, 2000).

Assim, a importância de uma gestão eficiente dos recursos disponíveis tem aparato legal e é reforçada pela participação crescente da população no acompanhamento das ações dos administradores públicos.

No Brasil, os municípios são os menores entes da federação, e com o processo de descentralização dos recursos, da gestão e das decisões governamentais - promovidas pela Carta Magna de 1988 - aumentaram sua autonomia passando a assumir maior importância na prestação de serviços de interesse local (BRASIL, 1988).

Quanto ao processo de descentralização de recursos, percebe-se aumento de receitas em favor dos municípios. Esta redistribuição financeira ocorreu por meio da ampliação das competências tributárias dos municípios, redução do poder de interferência da União sobre estes tributos e pelo aumento das transferências federais para essa esfera de governo.

Apesar dos indiscutíveis ganhos da autonomia, a arrecadação e aplicação da receita pública se apresentam como constantes desafios à gestão de finanças públicas municipais, posto que enquanto a população anseia o desenvolvimento local, o número de gestores com preparo para satisfazer esta necessidade é pequeno. Felizmente, este cenário tem sofrido alterações devido às exigências legais já mencionadas, elas estão balizando as decisões políticas.

No trabalho de Araújo e Oliveira (2000), é destacado que a arrecadação própria dos municípios brasileiros, no final da década de 1990, chegou a 1,6\% do PIB, apresentando uma elevação de $125 \%$ ao longo daquela década. Contudo, mesmo com o aumento da arrecadação municipal verificada no estudo, os autores salientam a existência de uma profunda dispersão dos indicadores entre cidades de economia e porte semelhante, revelando grandes espaços para aumento de carga tributária, especialmente nas localidades menos desenvolvidas.

Outro ponto a ser estudado refere-se à dependência financeira dos municípios brasileiros. Conforme Corrêa (2012), um estudo publicado pela Federação das Indústrias do Estado do Rio (Firjan), com base em dados que vão até o ano de 2010, 94\% dos municípios brasileiros têm nas transferências intergovernamentais pelo menos $70 \%$ de suas receitas correntes; e $83 \%$ não conseguem gerar nem $20 \%$ de suas receitas. Os fatores que explicam este comportamento estão ligados à localização geográfica do município, tamanho reduzido da população, deficiências na estrutura arrecadatória e, principalmente, má gestão. 
Neste contexto, surge a necessidade de analisar o comportamento das receitas do município de Parnaíba - PI, tanto por ser o segundo maior do Estado do Piauí e referência para a Região Norte, como também por sua importância econômica, política, histórica e cultural.

O estudo se embasa na seguinte proposição: Qual foi o comportamento da Receita Pública Municipal em Parnaíba - PI no decênio 2003-2012?

A partir desta proposta, objetiva-se revelar a dinâmica de arrecadação das receitas tributárias municipais, próprias e de transferências intergovernamentais, no município de Parnaíba - PI, verificando a representatividade de cada uma delas frente às arrecadações média e total dando enfoque às medidas administrativas que influenciaram a formação do cenário em estudo, que abrangeu o decênio 2003-2012 e demonstrar uma possível relação de dependência financeira que o município possui em relação às transferências intergovernamentais.

\section{FUNDAMENTAÇÃO TEÓRICA}

\subsection{A RECEITA PÚBLICA}

No Estado brasileiro, a partir da Constituição Federal de 1988, experimentou-se o fortalecimento do federalismo que, como se sabe, é uma forma de organização e de distribuição do poder estatal em que a existência de um governo central não impede que sejam divididas responsabilidades e competências entre ele e os Estados-membros. A descentralização, em seus aspectos: político, administrativo e fiscal, é o instrumento que dá configuração ao Estado Federal (BRASIL, 1988).

Quanto à descentralização fiscal, esta pode ser encarada como o conjunto de providências constitucionais, legais e administrativas orientadas ao financiamento dos diversos entes federados, seus órgãos, serviços e políticas públicas tendentes à satisfação das necessidades públicas nas respectivas esferas de competência (DOMINGUES, 2007).

Nesta problemática, pode ser citada como providência constitucional, a delegação de competência aos entes federados para a instituição de impostos, taxas e contribuições sociais e de melhorias; legais, as leis complementares $n^{\circ}$ 61/1989, $n^{\circ}$ 63/1990 e $n^{\circ}$ 91/1997, que dispõem sobre a repartição de receitas e distribuição de fundos a Estados e Municípios; e administrativas, as políticas públicas, sociais e econômicas, no âmbito do Sistema Único de Saúde (SUS) de que tratam os arts. 196 e 198 da Carta Magna (DOMINGUES, 2007).

$\mathrm{Na}$ busca pela compreensão do processo de composição dos recursos que custeiam as ações governamentais, devem ser considerados alguns conceitos, entre eles, o de Receita Pública.

Kohama (2003) define como receita pública todo e qualquer recolhimento feito aos cofres públicos, quer seja efetivado através de numerário ou outros bens representativos de valores - que o Governo tem o direito de arrecadar em virtude de leis, contratos ou quaisquer outros títulos de que derivem direitos a favor do Estado - quer seja oriundo de alguma finalidade específica, cuja arrecadação lhe pertença ou caso figure como depositário de valores que não lhe pertencerem.

Para maior compreensão a respeito da Receita Pública, cabe mencionar que, quanto à natureza, ela possui duas grandes classificações: Receita Pública Orçamentária e Receita 
Pública Extraorçamentária, entretanto, em virtude da finalidade desta produção, apenas a Receita Pública Orçamentária será vista com o detalhamento necessário. Verifiquem-se os conceitos no Quadro 01:

\section{Quadro 01 - Classificação da Receita Pública quanto à natureza}

\begin{abstract}
RECEITA PÚBLICA ORÇAMENTÁRIA
Conceito - é aquela discriminada na forma do Anexo III, da Lei $n^{\circ} 4.320 / 1964$ e que integra o orçamento público da entidade. Sua arrecadação depende de autorização legislativa, constante na própria lei do orçamento (lei orçamentária anual) e é realizada através da execução orçamentária. A receita pública orçamentária, quanto à categoria econômica, dividese em receitas correntes e receitas de capital:
\end{abstract}

A) Receitas correntes - segundo a Lei $n^{\circ}$ 4.320/1964, são receitas correntes as tributárias, de contribuições, patrimonial, agropecuária, industrial, de serviços e outras, e, ainda, as provenientes de recursos financeiros recebidos de outras pessoas de direito público e privado, quando destinadas a atender a despesas classificáveis em despesas correntes.

a.1) Receitas tributárias - são decorrentes da competência tributária instituída pela Constituição Federal. Os tributos compreendem os Impostos, as Taxas e as Contribuições de Melhoria.

Impostos: é a modalidade de tributo cuja obrigação tem por fato gerador uma situação independente de qualquer atividade estatal específica, relativamente ao contribuinte;

Taxas: tem como fato gerador o exercício regular do poder de polícia ou a utilização, efetiva ou potencial, de serviço público específico e divisível, prestado ao contribuinte ou posto à sua disposição;

Contribuições de melhoria: é instituída para fazer face ao custo de obras públicas de que decorra valorização imobiliária.

a.2) Transferências correntes - são as provenientes de recursos financeiros recebidos de outras pessoas de direito público ou privado quando destinadas a atender às despesas de manutenção e funcionamento conforme condições estabelecidas pela entidade repassadora ou pela própria administração da entidade, de acordo com as suas necessidades.

B) Receitas de capital - são Receitas de Capital, as provenientes da realização de recursos financeiros oriundos de constituição de dívidas; da conversão em espécie, de bens e direitos; os recursos recebidos de outras pessoas de direito público ou privado destinados a atender despesas classificáveis como Despesas de Capital e, ainda, o superávit do Orçamento Corrente. (Lei no 4.320, art. 11, § 2o)

\section{RECEITA PÚBLICA EXTRAORCAMENTÁRIA}

Conceito - é aquela que, embora previsível, não integra o orçamento fiscal dos entes federados e corresponde a fatos de natureza financeira decorrentes da própria gestão pública, como no caso de operações de crédito por antecipação de receita orçamentária, de cauções em dinheiro, de retenções da Previdência e outros.

Fonte - Manual do Gestor Público (2007); CNM (2008); Dias (2012); Souza (2014) 


\subsection{A RECEITA PÚBLICA MUNICIPAL}

O Município, como unidade político-administrativa, surgiu com a República Romana, interessada em manter a dominação pacífica sobre as cidades conquistadas. Os vencidos ficavam sujeitos, desde a anexação ao império, às imposições do Senado, mas, em troca da fiel obediência às leis romanas, a República concedia-lhes certas prerrogativas, que variavam de simples direitos privados até o privilégio político de eleger seus governantes e dirigir a própria cidade (MEIRELLES, 2003).

Já Rezende (2004) afirma que no Brasil Colonial nasceram os primeiros municípios, mas foi a Constituição de 1988 que os reconheceu como membros da federação em pé de igualdade com os Estados, no que diz respeito a direitos e deveres ditados pelo regime federativo.

Em conformidade com Matias e Campello (2000, p. 21), o município pode ser definido como "[...] o espaço físico onde ocorre a produção de bens e serviços, a circulação de mercadorias, e onde realmente são implementadas todas as ações, sejam de origem da esfera Federal, Estadual ou Municipal, ou de origem privada [...]”.

Sob esta ótica, o Município é reconhecido como a instituição que pode levar de forma mais eficiente e eficaz a presença do poder público ao interior do país, pois é nele onde se apresentam as condições mais adequadas para que seja formado um quadro nacional democrático e onde são geradas as situações mais favoráveis para intervenção, podendo desempenhar, também, o papel de agente do desenvolvimento econômico local (MENEZES, 2002).

Responsável pelo financiamento de atividades e realização dos fins da administração municipal, a Receita Pública Municipal é formada por recursos financeiros oriundos dos tributos municipais, preços pela utilização de bens ou serviços, ingressos provenientes das transferências intergovernamentais, advindas de financiamentos, empréstimos, subvenções, auxílios e doações de outras entidades ou pessoas físicas (CNM, 2008).

A despeito deste rol de recursos, a literatura consagra as receitas tributárias (próprias) e de transferências intergovernamentais como as de maior representatividade e sobre elas serão tecidos comentários.

Conforme a Lei 5.172/66, que instituiu o Código Tributário Nacional (CTN), art. $3^{\circ}$ : "tributo é toda prestação pecuniária compulsória, em moeda ou cujo valor nela se possa exprimir, que não constitua sanção de ato ilícito, instituída em lei e cobrada mediante atividade administrativa plenamente vinculada" (BRASIL, 1966).

Nogueira (1995) assevera que: "o direito de tributar do Estado decorre do seu poder de império pelo qual pode fazer 'derivar' para seus cofres uma parcela do patrimônio das pessoas sujeitas a sua jurisdição e que são chamadas receitas derivadas ou tributos”.

Para Sabbag (2011), a cobrança de tributos se mostra como a principal fonte das receitas públicas, voltadas ao atingimento dos objetivos fundamentais, insertos no art. $3^{\circ} \mathrm{da}$ Constituição Federal, tais como: a construção de uma sociedade livre, justa e solidária; a garantia do desenvolvimento nacional, a erradicação da pobreza e da marginalização, tendente a redução das desigualdades sociais e regionais, bem como a promoção do bem-estar da coletividade.

Tristão (2003) explica que a eficiência dos instrumentos tributários depende das esferas de governo e de suas competências tributárias. A teoria tradicional das Finanças Públicas estabelece que o Governo Federal deva ser o responsável pela arrecadação de 
impostos que requerem certo grau de centralização administrativa ou aqueles que afetam as políticas do país, como é o caso dos impostos sobre a renda e sobre o comércio exterior.

Em se tratando dos Estados, a tributação incide sobre o consumo e a circulação de bens. Já para os municípios, cabe-lhes assumir a responsabilidade pela tributação do patrimônio físico, como os impostos incidentes sobre a propriedade imobiliária (SOARES; FLORES; CORONEL, 2013).

A Carta Magna de 1988, o Código Tributário Nacional (CTN) e autores consagrados discriminam e detalham informações acerca dos tributos de competência exclusiva e comum dos municípios, estes, formam a chamada receita tributária (própria), expressos no Quadro 02:

\section{Quadro 02 - Componentes da Receita Tributária (própria)}

\begin{tabular}{|l|l|}
\hline \multicolumn{1}{|c|}{ RECEITA } & \multicolumn{1}{c|}{ DETALHAMENTO } \\
\hline $\begin{array}{l}\text { A) Imposto sobre a Propriedade Predial e } \\
\text { Territorial Urbana (IPTU) }\end{array}$ & $\begin{array}{l}\text { Tem como fato gerador a propriedade, o domínio útil } \\
\text { ou a posse de bem imóvel por natureza ou acessão } \\
\text { física, como definido na Lei Civil, localizado na zona } \\
\text { urbana do Município. }\end{array}$ \\
\hline $\begin{array}{l}\text { B) Imposto sobre a Transmissão Onerosa Inter } \\
\text { Vivos de Bens Imóveis e Direitos a ele Relativos }\end{array}$ & $\begin{array}{l}\text { O fato imponível é a transmissão inter vivos (entre os } \\
\text { vivos), por ato oneroso, a qualquer título (exceto por } \\
\text { doação, ainda que onerosa), de bens imóveis por } \\
\text { natureza ou acessão física. }\end{array}$ \\
\hline $\begin{array}{l}\text { C) Imposto sobre Serviços de Qualquer Natureza } \\
\text { (ISSQN) }\end{array}$ & $\begin{array}{l}\text { Tem como fato gerador a prestação de serviços, por } \\
\text { empresa ou profissional autônomo, com ou sem } \\
\text { estabelecimento fixo, de serviços de qualquer } \\
\text { natureza, definidos em Lei Complementar nacional, } \\
\text { desde que não estejam compreendidos na competência } \\
\text { dos Estados. }\end{array}$ \\
\hline D) Tributos de natureza comum & $\begin{array}{l}\text { São taxas e contribuições de melhoria que os } \\
\text { municípios podem instituir e cobrar, União e Estados } \\
\text { também podem fazê-los. }\end{array}$ \\
\hline
\end{tabular}

Fonte - CTN (1966); Nogueira (1995); Silva (1995); Alves e Freitas (2008)

De acordo com Silva (1995), muitos gestores municipais enfrentam dificuldades na arrecadação tributária, seja por motivos econômicos, administrativos ou políticos. Em decorrência disto, existe a necessidade de financiamento para atender às necessidades básicas da população como: educação e saúde; uma vez que os governos municipais são os executores das políticas públicas nacionais. Tais ações geram desequilíbrios nas finanças públicas dos municípios.

Assim, mesmo com uma estrutura de competências tributárias definida, existe a necessidade de um sistema de transferências intergovernamentais de recursos, com origem nos níveis superiores de governo (União e Estados), voltadas aos níveis inferiores (Municípios).

Neste contexto, as transferências intergovernamentais possuem papel fundamental na tarefa de promover uma distribuição adequada dos recursos arrecadados entre os entes federados, e no desenvolvimento regional no Brasil.

Conforme Gomes (2007), as transferências intergovernamentais constituem repasses de recursos financeiros entre entes descentralizados de um Estado, ou entre estes e o poder central, com base em determinações constitucionais, legais ou, ainda, em decisões GєECont, v.3, n.1, Floriano-PI, Jan-Jun. 2016. 
discricionárias do órgão ou entidade concedente, com vistas ao atendimento de determinado objetivo genérico.

Observa-se, no quadro 03, os principais recursos que formam as receitas de transferências intergovernamentais aos municípios:

Quadro 03 - Receitas transferidas pela União e Estados aos Municípios

\begin{tabular}{|c|c|}
\hline RECEITA TRANSFERIDA PELA UNIÃO & RECEITA TRANSFERIDA PELOS ESTADOS \\
\hline $\begin{array}{l}\text { A) Fundo de Participação dos Municípios (FPM) - } \\
\text { composto por 22,5\% do Imposto de Renda (IR) e do } \\
\text { Imposto sobre Produtos Industrializados (IPI), sendo } \\
\text { distribuído da seguinte maneira: } \\
\text { Municípios capitais: recebem } 10 \% \text { dos recursos do } \\
\text { FPM, a que se considerar neste repasse informações } \\
\text { como o tamanho da população e a renda per capita; } \\
\text { Municípios não capitais: recebem } 86,4 \% \text { dos } \\
\text { recursos do FPM, que são distribuídos segundo o } \\
\text { tamanho da população, com limites máximos e } \\
\text { mínimos; } \\
\text { Municípios não capitais, com população superior } \\
\text { a 156.216 habitantes: recebem } 3,6 \% \text { dos recursos } \\
\text { do FPM de acordo com os mesmos critérios } \\
\text { aplicados aos municípios capitais. }\end{array}$ & $\begin{array}{l}\text { A) Cota-parte do Imposto sobre Circulação de } \\
\text { Mercadorias e Serviços (ICMS) - da arrecadação do } \\
\text { ICMS, } 25 \% \text { é distribuída pelo Estado aos seus muni- } \\
\text { cípios, sendo que um mínimo de } 75 \% \text { deve ser } \\
\text { distribuído em função do valor agregado e } \\
\text { um máximo de } 25 \% \text { deve ser distribuí́o em função de } \\
\text { critérios estabelecidos pela legislação estadual. }\end{array}$ \\
\hline $\begin{array}{l}\text { B) Cota-parte do Imposto Territorial Rural (ITR) } \\
\text { - cabe aos municípios } 50 \% \text { do valor da arrecadação } \\
\text { do ITR. }\end{array}$ & $\begin{array}{l}\text { B) Cota-parte do Imposto sobre a Propriedade de } \\
\text { Veículo Automotor (IPVA) - o produto da } \\
\text { arrecadação do IPVA é repartido entre o Estado e o } \\
\text { município onde houver sido licenciado o veículo, } \\
\text { cabendo a cada um } 50 \% \text { do valor cobrado. }\end{array}$ \\
\hline $\begin{array}{l}\text { C) Imposto sobre Operações Financeiras/Ouro } \\
\text { (IOF-OURO) - do total arrecadado com o IOF- } \\
\text { OURO, 70\% destina-se aos municípios de origem. }\end{array}$ & - \\
\hline $\begin{array}{l}\text { D) Fundo de Compensação às Exportações (IPI } \\
\text { EXPORTAÇÃO) - composto por } 10 \% \text { da } \\
\text { arrecadação do IPI. Os municípios recebem } 1 / 3 \text { do } \\
\text { valor repassado ao Estado e a distribuição segue os } \\
\text { mesmos critérios do Imposto sobre Circulação de } \\
\text { Mercadorias e Serviços - ICMS. }\end{array}$ & - \\
\hline
\end{tabular}

Fonte - Pereira (2002)

Cabe aqui mencionar outra fonte de recursos para os municípios, que é proveniente da combinação de contribuições dos Estados, Distrito Federal e dos próprios Municípios e por isso chamada transferência multigovernamental: Fundo de Manutenção e Desenvolvimento da Educação Básica e Valorização dos Profissionais da Educação (FUNDEB) regulamentado no ano de 2007 pela Lei no 11.494, o FUNDEB substituiu o Fundo de Manutenção e Desenvolvimento do Ensino Fundamental e de Valorização do Magistério (FUNDEF), que vigorou de 1998 a 2006 (BRASIL, 2007).

\section{PROCEDIMENTOS METODOLÓGICOS}

No intuito de elucidar as questões que guiam a construção desta atividade acadêmica, optou-se pela realização de uma pesquisa bibliográfica com caráter exploratório. Conforme Marconi e Lakatos (2003), a pesquisa bibliográfica é um apanhado geral sobre os principais GєECont, v.3, n.1, Floriano-PI, Jan-Jun. 2016. 
trabalhos já realizados, revestidos de importância, por serem capazes de fornecer dados atuais e relevantes relacionados com o tema.

Quanto às formas de abordagem foram escolhidas as pesquisas qualitativa e quantitativa, isto porque, segundo Minayo (1993), a relação entre quantitativo e qualitativo não pode ser pensada como oposição contraditória, é de se desejar que as relações sociais possam ser analisadas em seus aspectos mais "concretos" e aprofundadas em seus significados mais essenciais. Assim, o estudo quantitativo pode gerar questões para serem aprofundadas qualitativamente e vice-versa.

Julgada como a estratégia de pesquisa que estabelecia maior conexão com o objetivo proposto, e considerando a opinião de Yin (2005) que, assim, diz: "a preferência pelo estudo de caso deve ser dada em situações em que os comportamentos relevantes não podem ser manipulados, mas quando é possível se fazer observações diretas e entrevistas sistemáticas", o Estudo de Caso foi eleito para esta pesquisa.

Feitas estas considerações, partiu-se para análise de dados secundários fornecidos pelo site da Secretaria do Tesouro Nacional - STN, nele, encontram-se Demonstrações Contábeis (Balanços Orçamentários), que permitiram analisar quantitativos das receitas tributárias e de transferências intergovernamentais, e construir o alicerce desta atividade.

Em seguida, procedeu-se análise quantitativa destas receitas em um período específico que compreendeu um decênio 2003-2012, a opção por este período deveu-se à disponibilidade de informações no site da Secretaria do Tesouro Nacional (STN) e compreendem os últimos dois anos de mandato (2003-2004) de um gestor municipal e dois mandatos integrais (20052012), de outro gestor. A importância desta informação se deve a compreensão de que diferentes planos de governo e seu sucesso ou não, podem produzir reflexos sobre o comportamento da Receita Municipal.

Considerando o fato de que os Balanços Orçamentários disponibilizados pelo site da Secretaria do Tesouro Nacional (STN) no decênio 2003-2012 foram elaborados com valores da moeda corrente à época da incorporação das receitas ao patrimônio, há que se considerar o desgaste da moeda no tempo, ou seja, para que se pudesse analisar o comportamento das receitas estudadas foi necessário realizar a atualização monetária dos valores; e para este procedimento usou-se a Unidade Fiscal de Referência (UFR) aplicada no município de Parnaíba e regulamentada em Decreto Municipal, com força de lei.

$\mathrm{Na}$ Tabela 01, pode se verificar os valores anuais da Unidade Fiscal de Referência (UFR) e respectivos índices de reajuste calculados com base na inflação do período.

Tabela 01 - Unidade Fiscal de Referência (UFR) do município de Parnaíba - PI em valores anuais 2003-2012.

\begin{tabular}{c|c|c}
\hline ANO & UFR & ÍNDICE DE REAJUSTE \\
\hline 2003 & 1,34 & - \\
\hline 2004 & 1,49 & $11,19 \%$ \\
\hline 2005 & 1,60 & $7,38 \%$ \\
\hline 2006 & 1,70 & $6,25 \%$ \\
\hline 2007 & 1,75 & $2,94 \%$ \\
\hline 2008 & 1,82 & $4,00 \%$ \\
\hline 2009 & 1,94 & $6,59 \%$ \\
\hline 2010 & 2,02 & $4,12 \%$ \\
\hline 2011 & 2,13 & $5,45 \%$ \\
\hline 2012 & 2,27 & $6,57 \%$ \\
\hline
\end{tabular}

GєECont, v.3, n.1, Floriano-PI, Jan-Jun. 2016. 
Fonte - Elaborada pela autora com base em dados da Secretaria de Fazenda do município de Parnaíba - PI (2014)

De posse destes dados, realizou-se uma análise quantitativa das receitas tributária e de transferências intergovernamentais por meio da construção de gráficos, o que permitiu verificar a representatividade de cada uma delas no volume total das Receitas Municipais. Esta construção também forneceu subsídios para a realização da análise comportamental, objetivo maior desta atividade.

Com este fim, foram realizadas entrevistas não padronizadas com perguntas abertas, dirigidas aos envolvidos no processo de arrecadação e/ou administração da Receita Municipal. Sendo assim, foram consultados: Diretor da Receita Municipal, Fiscal de Rendas Municipal, Assessora Executiva da Secretaria de Educação Municipal e o Gerente Regional da Secretaria de Fazenda do Estado do Piauí, no município de Parnaíba - PI. Vale ressaltar que todos os servidores públicos entrevistados realizaram atividades no período em estudo, e, por isso, conheciam as variáveis que poderiam explicar o comportamento das receitas.

Após o cumprimento das etapas elencadas na metodologia, cabe neste momento, apresentar a análise e discussão dos resultados obtidos.

\section{ANÁLISE E DISCUSSÃO DOS RESULTADOS}

Como se sabe, a Receita Pública Municipal em sua maior parte é formada pela soma da receita tributária e da receita de transferências intergovernamentais da União e dos Estados aos Municípios. Sendo assim, para verificação do comportamento destas receitas em Parnaíba - PI no decênio 2003-2012 optou-se pela análise isolada de seus componentes, dando enfoque a sua importância e as ações governamentais que possam ter influenciado sua dinâmica.

Conforme a Figura 1, ao serem elencadas as fontes de recursos que compõem a receita tributária (própria), o estudo constatou que o Imposto sobre Serviços de Qualquer Natureza (ISSQN) é a fonte mais significativa, sua arrecadação corresponde a 57,48\% da receita tributária média do município de Parnaíba - PI e 4,29\% da receita total.

O tributo apresenta comportamento de elevação praticamente constante, fato que segundo o diretor da Receita Municipal, deve-se a diversos fatores, entre eles: o aumento da fiscalização junto às empresas contribuintes deste tributo; acompanhamento do processo de inscrição de débitos na Dívida Ativa Municipal e a realização de Programas de Recuperação Fiscal, que promovem parcelamento especial de débitos de ISSQN recebíveis em até 180 dias.

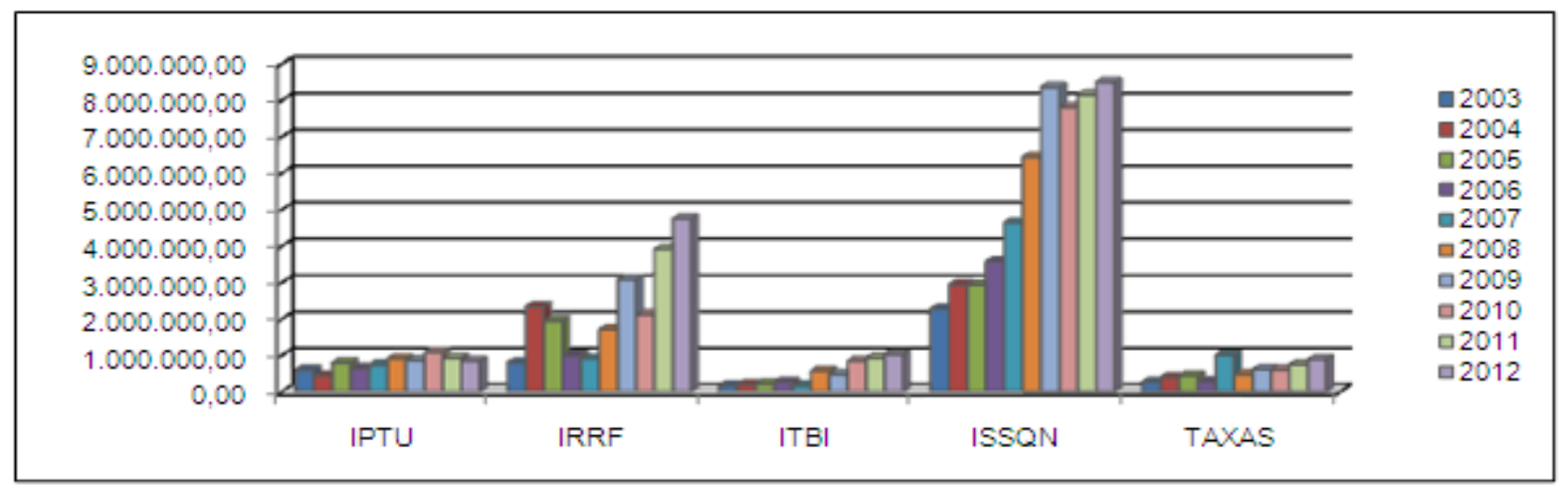

Figura 1: Receita Tributária arrecadada no município de Parnaíba - PI, decênio 2003-2012.

Fonte: Elaborado pela autora com base em dados da Secretaria do Tesouro Nacional - STN (2014). 
Representando $23,35 \%$ da receita tributária média e $1,74 \%$ da receita total do município, o Imposto de Renda Retido na Fonte (IRRF) merece destaque por ser o segundo maior em volume de arrecadação. Esta fonte de recursos é formada pelo valor retido sobre a remuneração paga aos servidores municipais e serviços prestados ao município.

Acerca do IRRF, o diretor da Receita Municipal relatou que Parnaíba - PI experimentou considerável elevação do número de servidores concursados e contratados no período estudado. O destaque é para o ano de 2010 quando o Município realizou concurso público abrangendo diversas áreas, esta é uma das prováveis explicações para a elevação da arrecadação ocorridas nos anos de 2011 e 2012, visto que a maioria das nomeações se deu neste período. O funcionário também mencionou o aumento das atividades do Setor de Licitações e Contratos Administrativos, segundo ele, assinaturas de contratos de grande vulto geraram consideráveis retenções deste tributo.

O Imposto sobre a Propriedade Predial e Territorial Urbana (IPTU) é a terceira fonte de recursos mais importante, compondo $8,75 \%$ da receita tributária média e $0,60 \%$ da receita total. Conforme informações fornecidas pelo diretor da Receita Municipal, a elevação do número de imóveis edificados por meio de Programas Sociais do Governo Federal e o crescimento de empreendimentos imobiliários têm sido os fatores responsáveis pelo volume de arrecadação deste tributo.

Entretanto, ao analisar a Figura 1 percebe-se certa inconstância no processo evolutivo de arrecadação do IPTU. Para o diretor da Receita Municipal, este comportamento se deve a diversos fatores, entre eles: a inadimplência que chega a 50\%; a não inscrição de débitos na Dívida Ativa Municipal - que já completa 10 (dez) anos - e a defasagem do Cadastro Imobiliário, que não sofre atualização há exatos 14 (quatorze) anos e poderia ampliar, consideravelmente, a base tributável.

As Taxas Municipais são arrecadadas para aplicação em gastos com exercício do poder de polícia ou com serviços públicos. Pela Lei Complementar $n^{\circ}$ 2.210/2005, que instituiu o Código Tributário do Município de Parnaíba - PI, as taxas que podem ser cobradas pelo ente são: de licença, publicidade, expediente, limpeza pública, coleta de lixo, conservação de calçamento e registro/inspeção sanitária.

De importância reduzida, as taxas municipais compõem 5,94\% da receita tributária média e $0,44 \%$ da receita total média.

Para o diretor da Receita Municipal, a única taxa que merece destaque pela elevação na arrecadação é a de licença para construção de bens imóveis, explicada, a exemplo da arrecadação de IPTU, pelo crescimento de empreendimentos imobiliários no município de Parnaíba - PI. Contudo, para o entrevistado, a cobrança de todas as taxas vem sendo prejudicada por desatualização da base de dados cadastrais mobiliário/imobiliário, e pelo reduzido quadro de servidores responsáveis pela fiscalização volante.

Com histórico de arrecadação bastante tímido, o Imposto sobre a Transmissão Onerosa Inter Vivos de Bens Imóveis e Direitos a ele Relativos (ITBI) é o tributo de menor relevância entre aqueles cobrados pelo município, pois contribui com apenas 5,07\% na composição da receita tributária média e $0,38 \%$ da receita total.

Segundo o entrevistado, apesar de algumas deficiências no processo arrecadatório, houve aumento do número de transferências imobiliárias, que se deve, principalmente, à multiplicação de empreendimentos imobiliários no município de Parnaíba - PI, ocorridos entre os anos de 2010 e 2012. 
$\mathrm{Na}$ Figura 2, onde se enumerou as fontes de recursos que compõem a receita de transferências intergovernamentais, o estudo constatou que o Fundo de Participação dos Municípios (FPM) é a receita de maior representatividade, seu recebimento constitui 37,87\% da média da receita de transferências e $35,04 \%$ da receita total. Segundo dados da Secretaria do Tesouro Nacional (STN), o FPM é uma das principais fontes de arrecadação de receitas na maioria dos municípios brasileiros.

O destaque na análise da Figura 2 é a queda brusca desta receita no ano 2008 e sua recuperação em períodos subsequentes. Como se sabe, a crise financeira iniciada em 2008 teve origem na economia norte-americana e resultou em impacto global. No Brasil, as medidas de contenção de seus efeitos passaram pela redução da alíquota de IRPF para estimular a demanda agregada, redução da alíquota de IPI incidente sobre automóveis e alguns eletrodomésticos da linha branca e pela desoneração do IOF sobre crédito ao consumidor. Apesar de seus efeitos positivos para saúde da economia nacional, estas medidas impactaram direta e negativamente o volume de repasses de FPM aos municípios, visto que seus componentes (IRPF e IPI) tiveram alíquotas reduzidas.

Contudo, prevendo abalos sobre a receita do FPM, o Governo Federal editou a Medida Provisória $\mathrm{n}^{\circ} 462$, em 14 de maio de 2009, que previa o pagamento aos municípios de montante equivalente à variação nominal negativa do FPM entre 2008 e 2009, sem a incidência de quaisquer descontos (saúde e FUNDEB). Assim, os municípios receberam em 2009 até quatro parcelas, distribuídas entre os meses de maio a outubro, com o objetivo de superar dificuldades financeiras emergenciais. Posteriormente, essa Medida Provisória foi convertida na Lei $\mathrm{n}^{\mathrm{o}}$ 12.058/2009 que ainda se encontra em vigor.

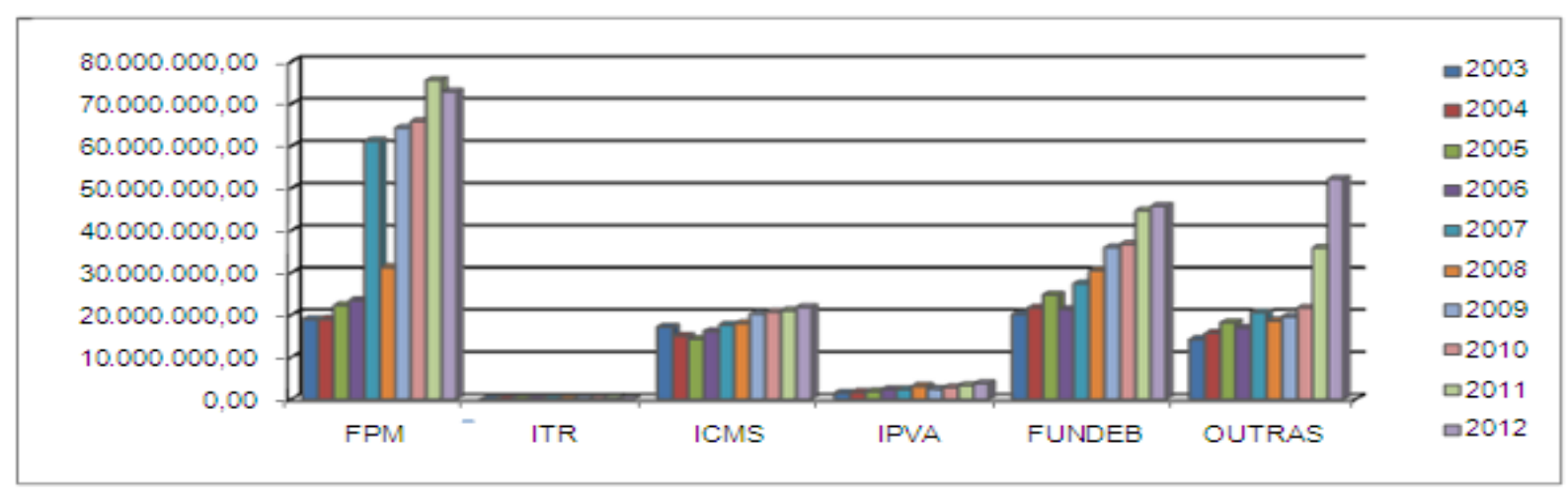

Figura 2: Receita Intergovernamental transferida para o município de Parnaíba - PI, no decênio 2003-2012. Fonte: Elaborado pela autora com base em dados da Secretaria do Tesouro Nacional - STN (2014).

Outra fonte de recursos que se destaca entre as receitas transferidas são as provenientes do Fundo de Manutenção e Desenvolvimento da Educação Básica e Valorização dos Profissionais da Educação (FUNDEB), que figura como a segunda principal. Compõe $25,73 \%$ da média da receita de transferências e $23,81 \%$ da receita total.

Conforme a assessora executiva da Secretaria de Educação Municipal, seu comportamento de elevação quase constante se deve ao aumento no número de matrículas nas escolas municipais, podendo ser atribuídas à construção de novas de unidades de ensino, incentivo a programas como EJA (Educação de Jovens e Adultos) e a Educação Especial, dirigida aos portadores de limitações físicas e mentais. 
Representando $19,45 \%$ na média da receita de transferências e $18,00 \%$ da receita total, fonte de receitas categorizada como Outras, é oriunda de transferências intergovernamentais pouco regulares, entre elas: Lei Complementar $n^{\circ}$ 86/97, Cota CIDE e Compensação Financeira pela Exploração de Recursos Minerais.

A Cota-parte do Imposto sobre Circulação de Mercadorias e Serviços (ICMS) é de grande relevância entre as receitas de transferências intergovernamentais ao Município de Parnaíba - PI, responde por $15,13 \%$ da média da receita de transferências e 14,00\% da receita total.

Segundo o gerente regional da Secretaria de Fazenda do Estado do Piauí no município de Parnaíba - PI, quanto às medidas adotadas para administração mais eficiente do ICMS, a operação de programas informatizados como: o Sistema de Arrecadação Tributária (SIAT web) e melhorias no Controle Interno da SEFAZ - PI são as de maior destaque.

Vale mencionar também que o fiscal de Rendas Municipal apontou a instalação de um parque para geração de energia eólica no município de Parnaíba - PI como responsável pelo incremento na arrecadação de ICMS a partir do ano de 2009.

Pouco destacada, a receita oriunda da Cota-parte do Imposto sobre a Propriedade de Veículo Automotor (IPVA) é responsável por 2,09\% da média da receita de transferências e $1,93 \%$ da receita total.

O gerente regional da Secretaria de Fazenda do Estado do Piaú, no município de Parnaíba - PI apontou a anistia de juros e multas concedida a contribuintes com débitos de IPVA, como uma das prováveis razões para a elevação do repasse ocorrido no ano 2008. O aumento de descontos para pagamento à vista (cota única) foi citado como responsável pela manutenção da arrecadação do IPVA nos anos posteriores.

A Cota-parte do Imposto Territorial Rural (ITR) é uma receita de transferência pouco relevante. Segundo o fiscal de Rendas Municipal, a mudança deste cenário poderia ocorrer por meio da celebração de convênio entre o município de Parnaíba - PI e a Secretaria da Receita Federal do Brasil. O convênio delegaria ao município as atribuições de fiscalização, lançamento e cobrança de créditos tributários relativos ao ITR, ou seja, em vez de o município receber da União 50\% do valor em forma de cota-parte, teria o valor integral ao arrecadá-lo.

Como objetivo secundário desta atividade, chama atenção a dependência financeira do município de Parnaíba - PI em relação à receita oriunda de transferências intergovernamentais. Dada à relevância da questão a Tabela 02 procura ilustrá-la.

Ao calcular-se a média da receita de transferências, percebe-se que ela corresponde a $92,63 \%$ da receita total, enquanto a média da receita tributária corresponde a apenas 7,37\% da receita total. Outro fato expressivo é o comparativo do valor monetário das receitas no ano de 2012, a receita de transferências intergovernamentais chega a ser 12 vezes maior que a receita tributária arrecadada.

Tabela 02 - Dependência financeira do município de Parnaíba (PI) em relação à Receita Intergovernamental transferida no decênio 2003-2012.

\begin{tabular}{c|c|c|c|c|c}
\hline Anos & $\begin{array}{c}\text { Rec. Disponível } \\
(\mathbf{A})\end{array}$ & $\begin{array}{c}\text { Transf. Intergovernamentais } \\
(\mathbf{B})\end{array}$ & $\begin{array}{c}\text { B/A } \\
(\boldsymbol{\%})\end{array}$ & $\begin{array}{c}\text { Rec. Tributárias } \\
(\mathbf{C})\end{array}$ & $\begin{array}{c}\text { C/A } \\
(\boldsymbol{\%})\end{array}$ \\
\hline 2003 & $72.360 .578,84$ & $68.227 .686,71$ & $94,28 \%$ & $4.132 .892,13$ & $5,72 \%$ \\
\hline 2004 & $79.302 .714,02$ & $72.953 .737,34$ & $91,99 \%$ & $6.348 .976,68$ & $8,01 \%$ \\
\hline 2005 & $87.565 .910,60$ & $81.207 .907,40$ & $92,74 \%$ & $6.358 .003,20$ & $7,26 \%$ \\
\hline 2006 & $85.792 .347,56$ & $80.014 .777,23$ & $93,27 \%$ & $5.777 .570,33$ & $6,73 \%$ \\
\hline 2007 & $136.763 .670,92$ & $129.282 .668,68$ & $94,53 \%$ & $7.481 .002,24$ & $5,47 \%$ \\
\hline
\end{tabular}

GєECont, v.3, n.1, Floriano-PI, Jan-Jun. 2016. 


\begin{tabular}{c|c|c|c|c|c}
\hline 2008 & $111.579 .609,64$ & $101.447 .698,88$ & $90,92 \%$ & $10.131 .910,76$ & $9,08 \%$ \\
\hline 2009 & $155.803 .125,34$ & $142.397 .427,89$ & $91,40 \%$ & $13.405 .697,45$ & $8,60 \%$ \\
\hline 2010 & $160.294 .275,60$ & $147.810 .995,42$ & $92,21 \%$ & $12.483 .280,18$ & $7,79 \%$ \\
\hline 2011 & $195.430 .380,93$ & $180.730 .129,30$ & $92,48 \%$ & $14.700 .251,63$ & $7,52 \%$ \\
\hline 2012 & $212.396 .541,49$ & $196.371 .996,92$ & $92,46 \%$ & $16.024 .544,57$ & $7,54 \%$ \\
\hline Total & $\mathbf{1 . 2 9 7 . 2 8 9 . 1 5 4 , 9 4}$ & $\mathbf{1 . 2 0 0 . 4 4 5 . 0 2 5 , 7 7}$ & - & $\mathbf{9 6 . 8 4 4 . 1 2 9 , 1 7}$ & - \\
\hline
\end{tabular}

Fonte: Elaborada pela autora com dados fornecidos pela Secretaria do Tesouro Nacional - STN (2014)

Perguntado a respeito deste cenário, o diretor da Receita Municipal citou o reduzido quadro de servidores e a desatualização de programas informatizados de arrecadação como prováveis explicações para o elevado nível de dependência.

O município de Parnaíba - PI é o segundo maior do estado, perdendo apenas para Teresina (Capital), tem atividade comercial intensa, apresenta crescimento do setor de serviços e multiplicação de empreendimentos imobiliários. Por isso, apesar das justificativas aqui mencionadas, a situação de dependência financeira é preocupante e merece aprofundamento por parte do Poder Público Municipal.

\section{CONCLUSÕES}

A Receita Pública Municipal, formada em grande parte pelas receitas tributárias e de transferências intergovernamentais da União e dos Estados, é a mola propulsora das atividades designadas como de responsabilidade das gestões locais e tem como finalidade o bem-estar da população alcançada.

O estudo embasou-se na seguinte proposição: Qual foi o comportamento da Receita Pública Municipal em Parnaíba - PI no decênio 2003-2012?

A partir desta proposta objetivava-se revelar a dinâmica de arrecadação das receitas tributárias municipais, próprias e de transferências intergovernamentais, no município de Parnaíba - PI, verificando a representatividade de cada uma delas frente às arrecadações média e total dando enfoque às medidas administrativas que influenciaram a formação do cenário em estudo, que abrangeu o decênio 2003-2012 e demonstrar uma possível relação de dependência financeira que o município possui em relação às transferências intergovernamentais.

A metodologia adotada envolveu análises bibliográficas e documental e teve como formas de abordagem as pesquisas qualitativa e quantitativa. Como fonte de dados primários deu-se a realização de entrevistas com profissionais envolvidos no processo de arrecadação e/ou administração de tributos; e de dados secundários a coleta de informações no site da Secretaria do Tesouro Nacional (STN). Elegeu-se como estratégia de pesquisa o Estudo de Caso, ou seja, a avaliação específica das receitas arrecadadas e transferidas ao município de Parnaíba - PI. Realizou-se atualização monetária das receitas para que fosse possível adequálas ao período do estudo e guiou-se por gráficos e tabelas para a análise pretendida.

Os resultados demonstram elevação na arrecadação da maior parte das receitas do município, apesar das grandes oscilações. O estudo evidenciou a composição da receita tributária, que em ordem decrescente de representatividade têm como fontes: o Imposto sobre Serviços de Qualquer Natureza (ISSQN), que responde por 57,48\% da receita tributária média; o Imposto de Renda Retido na Fonte (IRRF), com participação de 23,35\%; o Imposto sobre a Propriedade Predial e Territorial Urbana (IPTU), que contribui com 8,15\%; as Taxas Municipais, que respondem por 5,94\% e o Imposto sobre a Transmissão Onerosa Inter Vivos

GєECont, v.3, n.1, Floriano-PI, Jan-Jun. 2016. 
de Bens Imóveis e Direitos a ele Relativos (ITBI), que colabora com 5,07\% para a formação da receita tributária média.

A pesquisa também apresentou a composição da receita de transferências intergovernamentais que, em ordem decrescente de relevância, têm como fontes: o Fundo de Participação dos Municípios (FPM), que contribui com 37,87\% para a formação da média da receita de transferências; o Fundo de Manutenção e Desenvolvimento da Educação Básica e Valorização dos Profissionais da Educação (FUNDEB), que coopera com 25,73\%; as Outras receitas que respondem por 19,45\%; a Cota-parte do Imposto sobre Circulação de Mercadorias e Serviços (ICMS), que auxilia com 15,13\%; a Cota-parte do Imposto sobre a Propriedade de Veículo Automotor (IPVA), que colabora com 2,09\% e a Cota-parte do Imposto Territorial Rural (ITR), com participação irrisória na composição da média receita de transferências.

Destaca-se a existência de grande dependência financeira em relação aos recursos oriundos de transferências intergovernamentais em detrimento da receita tributária (própria), uma situação que merece aprofundamento por parte do Poder Público Municipal.

Ressalta-se que a Prefeitura Municipal de Parnaíba - PI vem nos últimos anos implementando medidas que estão contribuindo para o aprimoramento das ferramentas arrecadatórias no intuito de elevar sua receita tributária (própria) e reduzir a dependência dos recursos provenientes de transferências intergovernamentais, entre elas: atualização da Planta Genérica de Valores (PGV), que melhorará a arrecadação do IPTU; implantação da Nota Fiscal Eletrônica (e - Nota), de grande importância no processo de gestão do ISSQN e elevação de incentivos financeiros aos Auditores Fiscais do Município para o fomento à fiscalização, tão necessária ao processo de arrecadação.

Desta maneira, verificou-se que o estudo das receitas tributárias municipais constitui tema de grande relevância, pois representam um desafio diário aos gestores públicos municipais que devem geri-las de forma a atender aos mais variados anseios sociais.

Entre as limitações para a confecção deste trabalho, pode-se mencionar a resistência oferecida por alguns servidores públicos em conceder informações mais detalhada a respeito do processo de arrecadação e/ou administração de receitas municipais e a desatualização da base de dados financeiros e orçamentários disponíveis no site da Prefeitura Municipal de Parnaíba - PI.

Recomenda-se a elaboração de outros trabalhos com o mesmo enfoque, em períodos anterior e/ou posterior ao abarcado por esta atividade, de forma que o município passe a dispor de um estudo completo a respeito da dinâmica de arrecadação de suas receitas e, também, a feitura de pesquisas que contemplem o comportamento das despesas municipais, de maneira que possam realizar-se estudos comparativos entre a evolução da arrecadação de receitas e da realização de despesas, que serão de grande relevância para o aprimoramento das ferramentas de gestão responsável dos recursos públicos.

\section{REFERÊNCIAS}

BRASIL. Código Tributário Nacional: Lei no 5.172, de 25 de Outubro de 1966. Dispõe sobre o Sistema Tributário Nacional e institui normas gerais de direito tributário aplicáveis à União, Estados e Municípios.

ALVES, E. C.; FREITAS, V. P. Código Tributário Nacional comentado: doutrina e jurisprudência, artigo por artigo, inclusive ICMS e ISS. Brasília: BDJur, 2008.

GєECont, v.3, n.1, Floriano-PI, Jan-Jun. 2016. 
ALVES, F. O. et. al. O Plano Plurianual (PPA). Atividade acadêmica. Curso de PósGraduação em Gestão e Contabilidade Pública. Universidade Estadual do Piauí, Parnaíba, PI, 2013.

ARAÚJO, E.; OLIVEIRA, P. A. Tributação municipal: desigualdades na carga tributária local (1996). Informe-se BNDES, São Paulo, n. 15, p. 1-8, jul. 2000.

BRASIL, CONTAS anuais. Ministério da Fazenda (Secretaria do Tesouro Nacional). Disponível em: <http://www.tesouro.fazenda.gov.br/contas-anuais>. Acesso em: 10 ago. 2014.

CHIAVENATO, I. Teoria Geral da Administração. 6 ed. rev. e atualizada. Rio de Janeiro: Elsevier, 2001.

Confederação Nacional dos Municípios - CNM. Finanças Públicas: Noções Básicas para os Municípios. Brasília : CNM, 2008.

Controladoria Geral do Estado do Piauí - CGE/PI. Manual do Gestor Público: orientações técnicas e procedimentos administrativos e financeiros. $2^{\mathrm{a}}$ ed. Teresina, 2007. $300 \mathrm{p}$.

CORRÊA, A. Por que a maioria dos Municípios Brasileiros não se sustenta? . Disponível em: 〈http://jornalggn.com.br/blog/luisnassif/a-dependencia-financeira-dos-municipios>.

Acesso em: 19 ago. 2014.

DIAS, R. R. Contabilidade aplicada ao setor público: para o exame de suficiência do CFC: bacharel em ciências contábeis. $1^{a}$ ed. São Paulo: EDIPRO, 2012.

DOMINGUES, J.M. Federalismo fiscal brasileiro. Texto apresentado no II Congresso Internacional de Direito Tributário da Cidade do Rio de Janeiro. 9 a 11 de maio de 2007. Disponível em http://www.idtl.com.br/artigos/186.pdf.

GOMES, E. C. da S. Fundamentos das transferências intergovernamentais. Jus Navigandi, Teresina, ano 12, n. 1580, 29 out. 2007.

KOHAMA, H. Balanços públicos: teoria e prática. São Paulo: Atlas, 1999.

MARCONI, M. de A.; LAKATOS, E. M. Fundamentos da metodologia científica. 5. ed. São Paulo: Atlas, 2003.

MATIAS, A. B.; CAMPELLO, C. A. G. B. Administração Financeira Municipal. São Paulo: Atlas, 2000. 413p.

MEIRELLES, H. L. Direito Administrativo Brasileiro. $28^{a}$ ed. São Paulo: Malheiros Editores, 2003.

MENEZES, A. M. F. O processo de descentralização e as contas públicas: um estudo sobre as bases financeiras municipais baianas. 2002. 189 f. Tese (Doutorado em Administração) Curso Doutorado em Administração, Universidade Federal da Bahia, Salvador, 2002.

MINAYO, M. C. de S.; SANCHES, O. Quantitativo-Qualitativo: oposição ou complementariedade? Caderno Saúde Pública., v. 9, n. 3, p. 239-262, 1993.

NOGUEIRA, R. B. Curso de Direito Tributário. 14. ed. São Paulo: Saraiva, 1995.

PARNAÍBA. Lei Complementar $n^{\circ} 2.210$, de 28 de Dezembro de 2005. Dispõe sobre o Código Tributário do Município de Parnaíba, e dá outras providências.

PEREIRA, J. A. M. Finanças Públicas Municipais: relação de dependência entre receita transferida e receita própria dos municípios do estado do rio grande do sul. período 1989- 
1998. Atividade acadêmica. Universidade Regional do Noroeste do Estado do Rio Grande do Sul, Ijuí, RS, 2002.

REZENDE, Fernando. Integração regional e harmonização tributária: a perspectiva brasileira. Inter-American Development Bank, 2004.

SABBAG, E. Manual de Direito Tributário. 3. ed. São Paulo: Saraiva, 2011.

SILVA, V. M. da. Os Municípios Paulistas e o Federalismo Fiscal Brasileiro. São Paulo: IMESP; CEPAM, 1995.

SOARES, C. S.; FLORES, S. A. M. F.; CORONEL, D.A. Receita Pública Municipal: um estudo sobre o comportamento das receitas próprias e de transferência no município de Santa Maria/RS. Anais... Congresso Internacional de Administração, 10., 2013, Paraná. Ponta Grossa: DEADM/UEPG, 2013.

SOUZA, A. F. de. Contabilidade Pública. [S. 1.], 2014. (Apostila)

TRISTÃO, J. A. M. A Administração Tributária dos Municípios Brasileiros: uma avaliação do desempenho da arrecadação. São Paulo: EAESP/FGV, 2003, 172 p. (Tese de doutorado apresentada ao Curso de Pós - Graduação da EAESP/FGV. Área de Concentração: Organização, Recursos Humanos e Planejamento).

YIN, R. K. Estudo de caso: planejamento e método. Porto Alegre: Bookman, 2005. 